\title{
More Rapid Sleep Onset with Lingual-Spray vs Oral-Tablet Delivery Zolpidem
}

\author{
Robert B. Raffa ${ }^{1,2}$, Gerwin Westfield ${ }^{3}$ \\ ${ }^{1}$ Univ Arizona College of Pharmacy, Tucson, AZ, USA \\ ${ }^{2}$ Temple Univ School of Pharmacy, Philadelphia, PA, USA \\ ${ }^{3}$ AytuBioScience, Englewood, CO, USA \\ Email: robert.raffa@temple.edu
}

How to cite this paper: Raffa, R.B. and Westfield, G. (2019) More Rapid Sleep Onset with Lingual-Spray vs Oral-Tablet Delivery Zolpidem. Pharmacology \& Pharmacy, 10, 329-342.

https://doi.org/10.4236/pp.2019.107027

Received: May 31, 2019

Accepted: July 28, 2019

Published: July 31, 2019

Copyright () 2019 by author(s) and Scientific Research Publishing Inc. This work is licensed under the Creative Commons Attribution International License (CC BY 4.0).

http://creativecommons.org/licenses/by/4.0/

(c) (i) Open Access

\begin{abstract}
Insomnia and related sleep disorders (somnipathies) affect a large segment of the population, and result in a significant negative impact on quality of life and reduced or lost productivity. The speed of sleep onset is a critical characteristic of successful pharmacotherapeutic intervention for insomnia. Zolpidem, a non-benzodiazepine benzodiazepine receptor agonist (nBzRA) is widely used to treat insomnia. Although not itself a benzodiazepine (BZD), zolpidem has high binding affinity for the benzodiazepine receptor, which acts as a positive allosteric modulator of the GABAA receptor complex. It therefore increases the neuronal transmembrane influx of $\mathrm{Cl}^{-}$ions, thereby decreasing neuronal excitability and promoting sleep. In this four-way crossover, dose-ranging, multiple-treatment study, a lingual spray formulation of zolpidem was safe and well-tolerated and yielded more rapid pharmacokinetics (mean plasma concentration) and efficacy (visual analog scale and digit symbol substitution test) compared to oral tablets.
\end{abstract}

\section{Keywords}

Zolpidem, Lingual Spray, Pharmacokinetics, Efficacy, Safety/Tolerability, AMBIEN

\section{Introduction}

Sleep is necessary for maintaining and promoting good health. In contrast, inadequate or poor sleep has the opposite, negative, effect on quality of life, health, and performance. Disruptions of sleep quality or of sleep pattern occur in many forms and to variable degrees that result in sleep disorders (somnipathies). Chronic insomnia affects an estimated $10 \%$ of the population resulting in not only poor 
sleep, but also poor daytime functioning [1]. It leads to falls [2], motor vehicle accidents, increased healthcare utilization [3], worsening of comorbid and psychiatric disorders [4] [5] [6] [7], and even decreased survival rates [8]. Thus, treatment can provide a medical, as well as quality of life, benefit [9] [10] [11].

\subsection{Sleep Problems}

Somnipathies can impact different aspects of good quality sleep. They include difficulty falling asleep (i.e., onset latency), and/or staying asleep (disturbance of sleep maintenance, and the subtype of middle-of-the-night wakefulness), poor quality sleep (viz., not refreshing), or some combination of these. All can lead to poor health and quality of life problems.

\subsection{Treatment Recommendations}

There are two widely accepted treatments for insomnia: cognitive behavioral therapy for insomnia (CBT-I) and pharmacotherapy [1] [12]. CBT-I is a structured behavioral approach typically including education and training in relaxation techniques, good sleep hygiene, stimulus control, sleep restriction, and cognitive techniques, which designed to identify and mitigate negative cognitive and behavioral influences on sleep [13].

The pharmacotherapeutic approach usually works much more rapidly than CBT-I does (minutes vs weeks), and is just as effective short-term, but it might have less carry-over effect than CBT-I [1] [13]. And of course CBT-I carries no risk of adverse effects. However, CBT-I availability is limited, time-consuming, and expensive. Less than 5\% of chronic insomniacs utilize CBT-I, [14] and pharmacotherapy remains the primary treatment $[1]$.

\section{Pharmacologic Options}

Insomnia often involves some combination of a state of hypervigilance during the day and difficulty initiating and maintaining sleep at night [15] [16] [17]. Many medical factors contribute to poor sleep, which implicate physiological underpinnings [18] [19] [20]. And insomnia is often associated with altered levels of hormones and other biochemical factors [18] [21] [22]. Therefore, a pharmacotherapeutic approach makes sense in such situations [23] [24].

Pharmacologic treatment options include [25] short or intermediate acting BZDs, non-BZD BzRAs (such as zolpidem), melatonin agonist (e.g., ramelton), sedating antidepressant (e.g., trazodone, amitriptyline, doxepinemitazapine), sedating antiepilepsy or antipsychotic medications, or combinations of these. The therapies that traditionally have had the best therapeutic index (efficacy and safety) have been those that interact with the GABA-ergic system.

\subsection{GABA and $\mathrm{GABA}_{A}$ Receptor Complex}

The inhibitory amino acid GABA ( $\gamma$-aminobutyric acid) acts through the $\mathrm{GABA}_{\mathrm{A}}$ receptor to play an important role in sleep/wake cycles [26] [27] [28]. Binding of 
either GABA itself or an exogenous agonist analog to the $\mathrm{GABA}_{\mathrm{A}}$ receptor, which is a ligand-gated ionotropic type receptor, increases $\mathrm{Cl}^{-}$ion influx down its concentration difference from the extracellular side to the intracellular side of neurons. Since the neuronal transmembrane resting potential difference is already negative, the influx of $\mathrm{Cl}^{-}$hyperpolarizes the neuron, i.e., increases the transmembrane potential difference, producing a post-synaptic inhibitory potential (IPSP). The resultant hyperpolarization means that the neuron is less likely to fire in response to an excitatory input, which favors sleep.

\subsection{Benzodiazepines}

Because of their efficacy and safety in short-term use, BZDs have been popular choices for short term treatment of insomnia. BZDs produce their effect by binding to specific sites (BzRs) on the $\mathrm{GABA}_{\mathrm{A}}$ receptor complex, producing allosteric modulation, inhibition of neuronal excitation, and an increase in speed of sleep onset and increase in total sleep time [29] [30] [31]. The BZDs represent an advance over preceding sedatives, including barbiturates, in that they are more selective and produce fewer adverse effects. However, they also have the potential for tolerance and dependence, and produce their own set of adverse effects such as disruption of psychomotor function, impairment of memory, paradoxical excitement, depression, and potential teratogenicity. [32] And they are a special problem for elderly patients, because of the potential for cognitive impairment, delirium, falls, and bone fractures [33]. In response to the problems associated with the BZDs, non-BZD BzRAs were developed to minimize adverse effects and abuse potential associated with the BZDs.

\subsection{Zolpidem}

Chemically, zolpidem is an imidazopyridine, not a benzodiazepine, but pharmacologically it acts the same way, that is, as a benzodiazepine receptor agonist. It displays selective binding affinity and functional efficacy at $\mathrm{GABA}_{\mathrm{A}}$ receptors that contain $\alpha 1$ subunits [19]. Since subunits in addition to $\alpha$-1 have been associated with sedative action and sleep continuity, the molecular mechanism underlying the clinical efficacy of zolpidem's hypnotic action is likely to involve subunits other than $\alpha-1$.

Zolpidem's pharmacokinetics and efficacy favor its short-term use for insomnia: it is rapidly distributed to the central nervous system [34], it does not have active metabolites, it is rapidly eliminated, and it does not accumulate after repeated administration [35]. And in most patients it reduces sleep latency [36] [37], without altering sleep stages [38], it does not cause residual morning-after effects [38] [39] [40] [41] [42], and it does not cause rebound insomnia after short-term administration [36] [43] [44].

As a result of its favorable pharmacologic properties, zolpidem is the active ingredient in several products commercially marketed to treat insomnia. The lingual spray offers a means of administration that has the advantages of easy access (favors better compliance), and distribution onto a large and highly-vascularized surface area (Figure 1). 


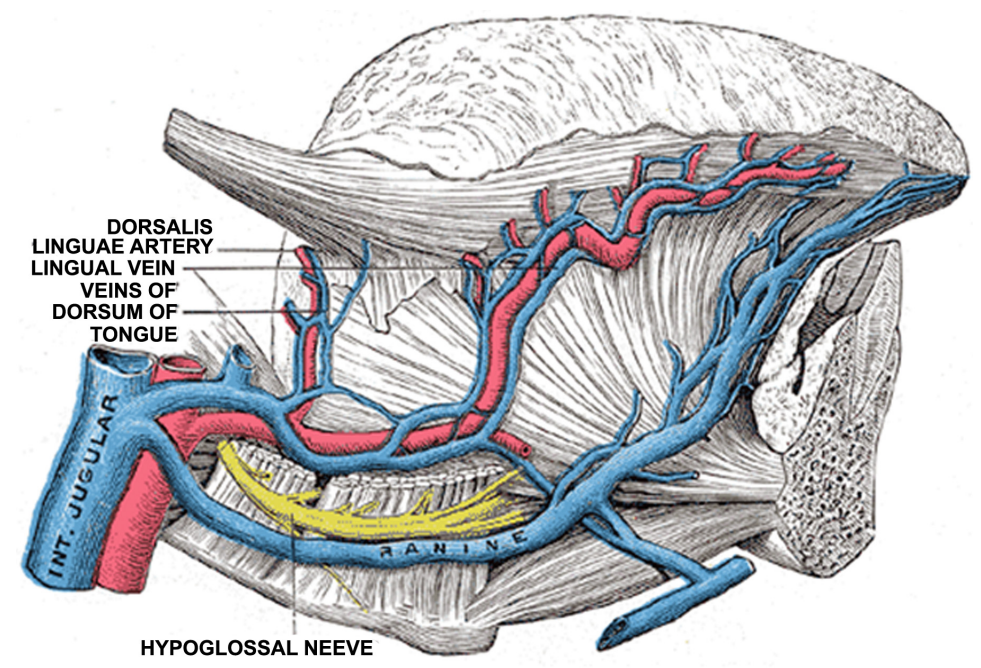

Figure 1. Anatomy of blood vessels of tongue. From WikiMedia commons.

\section{Challenges}

\subsection{Oral Route}

Speed of sleep onset is important for treatment of insomnia. Sleep latency (the time it takes to fall asleep) relates to sleep efficiency (the proportion of bedtime asleep), because if a person is able to fall asleep quickly, they are more likely to have an efficient sleep, and cycle normally through rapid eye movement sleep (REM) and non-rapid eye movement sleep. The oral route is relatively slow compared to other routes and subjects a drug to a first-pass metabolism effect. Thus, bioavailability is generally low and slow compared to other routes. Additionally, this can be a problematic delivery modality for patients with dysphagia, or elderly patients that have difficulty swallowing tablets.

\subsection{Dose Variance of Generics}

Consistency of dose is another important characteristic that is favorable for treatment of insomnia. Although bioequivalence is defined and required by regulatory control, caution is warranted, even if in a minority of situations [45] [46].

\section{Methods}

The present study was designed in a manner to determine the pharmacokinetics, therapeutic efficacy, and safety/tolerability of two doses of zolpidem lingual spray (LS) compared to orally-administered drug in fasted $(\geq 10-\mathrm{h})$ young healthy volunteers ( $\mathrm{N}=20$ males, 23 females).

\subsection{Study Design}

This was a single-center, four-way crossover, open-label, dose-ranging, multiple-treatment study. There were four treatment groups: zolpidem oral tablets (AMBIEN, 5 or $10 \mathrm{mg}$ ) and zolpidem LS (5 or $10 \mathrm{mg}$ ). Zolpidem LS was admi- 
nistered to each study participant, without water, by spraying the drug formulation into the mouth (one actuation of the pump $=5 \mathrm{mg}$; two actuations of the pump = $10 \mathrm{mg}$ ). The participants were instructed not to swallow for a period of 30 seconds and to avoid intentional swallowing for up to five minutes following dosing, if possible. AMBIEN was administered with water. Treatments were separated by a period of about one week.

\subsection{Participants}

A total of 48 healthy male and female participants $\left(18-45\right.$ yo, BMI $\left.\leq 30 \mathrm{~kg} / \mathrm{m}^{2}\right)$ were enrolled; 45 completed the study. The three participants did not complete the study due to (one each): vomiting after receiving AMBIEN (10 mg), unrelated personal incident, vomiting after receiving zolpidem LS (10 mg). Most of the participants were Caucasian $(\mathrm{N}=22)$ or Black $(\mathrm{N}=18)$, the remainder were Hispanic $(\mathrm{N}=2)$ or Asian $(\mathrm{N}=1)$. The mean age of the participants in the analyses was 29.3 years (range $=19-45 \mathrm{yr}$ ), the mean weight was $74 \mathrm{~kg}$ (range $=55$ - $95 \mathrm{~kg}$ ), and the mean BMI was $26 \mathrm{~kg} / \mathrm{m}^{2}\left(22-30 \mathrm{~kg} / \mathrm{m}^{2}\right)$.

\subsection{Pharmacokinetic Measures}

Measurements of plasma concentrations of zolpidem were made using a validated high-performance liquid chromatography (HPLC) method with mass spectrometric (MS/MS) detection methodology. Plasma samples were spiked with an internal standard, zolpidem- $\mathrm{d}_{6}$, processed by protein precipitation, and analyzed using reversed-phase HPLC with MS/MS detection.

Pharmacokinetic parameters were calculated for each participant from the plasma concentration levels of zolpidem. The area under the concentration-time curve (AUC), maximum drug concentration $\left(\mathrm{C}_{\max }\right)$, time to maximum drug concentration $\left(\mathrm{T}_{\max }\right)$, time to first detectable drug concentration $\left(\mathrm{T}_{\mathrm{det}}\right)$, time to plasma drug concentration associated with sedation $(\geq 20 \mathrm{ng} / \mathrm{mL})\left(\mathrm{T}_{\text {ther }}\right)$, elimination half-life $\left(t_{1 / 2}\right)$, and other parameters were evaluated.

\subsection{Efficacy Measures}

Two primary measures were used. For one measure, within 15 minutes prior to dosing and at 12 and 22 minutes after dosing, each of the participants self-assessed their level of drowsiness using a scale ranging from "a little" to "a lot" on a $100-\mathrm{mm}$ visual analog scale (VAS) for each of 12 descriptors of sedation. For the other measure, at the same visits, the participants performed the Digit Symbol Substitution Test (DSST), which is an assessment of attention, perceptual speed, motor speed, visual scanning and memory, within 15 minutes prior to dosing and at 13 and 23 minutes after dosing. During the DSST assessment, each participant was given a piece of paper with 9 symbols corresponding to 9 digits. Below these were 3 rows of digits with empty boxes. The participants were asked to fill in as many corresponding symbols as possible within 90 seconds. 


\section{Results}

The present study was designed in a manner to determine the pharmacokinetics, efficacy, and safety/tolerability of two doses of zolpidem lingual spray (LS) compared to an orally-administered drug formulation (oral tablets) in fasted ( $\geq 10-\mathrm{h}$ ) young healthy volunteers ( $\mathrm{N}=20$ males, 23 females).

\subsection{Pharmacokinetics}

An analysis of bioequivalence comparing each treatment group to each of the others when the data were normalized to a dose of $10 \mathrm{mg}$ revealed:

- The $5 \mathrm{mg}$ AMBIEN tablet was not bioequivalent with the $10 \mathrm{mg}$ AMBIEN tablet

- Zolpidem LS 5 and $10 \mathrm{mg}$ doses were bioequivalent to the $10 \mathrm{mg}$ AMBIEN tablet

- There was a gender-effect irrespective of dose normalization in which $\mathrm{C}_{\max }$, $\mathrm{AUC}_{0 \rightarrow \mathrm{T}}$, and $\mathrm{AUC}_{0 \rightarrow \infty}$ are significantly higher in females than in males, with a significantly longer half-life and slower clearance also observed in female participants

- There was no gender-treatment effect found in any of the pharmacokinetic analyses

- There was no treatment-effect found in any of the pharmacokinetic analyses

\subsubsection{Plasma Levels}

The results for mean plasma concentration for all groups (zolpidem LS 5 and 10 $\mathrm{mg}$ and AMBIEN 5 and $10 \mathrm{mg}$ ) as a function of time during the first 20 minutes following administration are shown in Figure 2. This time window relates to the

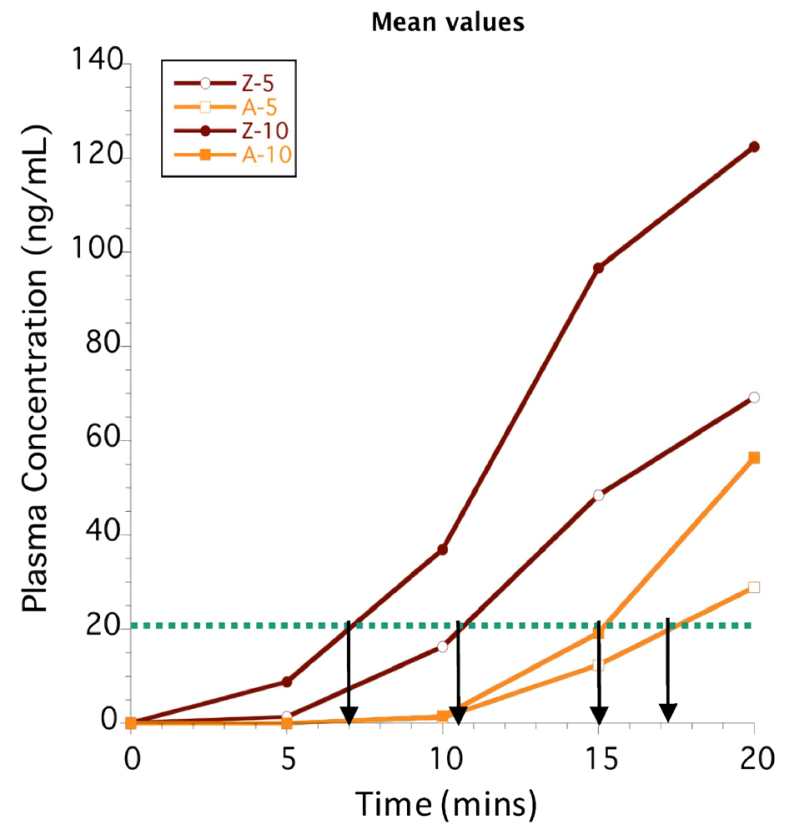

Figure 2. Mean plasma concentration following $5 \mathrm{mg}$ or $10 \mathrm{mg}$ zolpidem LS (Z) or tablets (A). 
time of onset of therapeutic effect and allows comparison of the formulations. As expected, there is a dose-related relationship for both formulations. That is, the 10 -mg dose of each formulation (zolpidem LS and AMBIEN) resulted in a more rapid increase in plasma concentration of zolpidem than did the 5-mg dose of each formulation (intra-formulation comparison).

With regard to comparison of the two formulations (inter-formulation comparison): the plasma concentration of zolpidem rose more rapidly after 5-mg zolpidem LS compared to 5-mg AMBIEN (Figure 3), and the plasma concentration of zolpidem rose more rapidly following $10-\mathrm{mg}$ zolpidem LS compared to 10-mg AMBIEN (Figure 3). In fact, the 5-mg dose of zolpidem LS formulation resulted in a faster increase in zolpidem plasma concentration than did the 10-mg dose of AMBIEN (Figure 2).

\subsubsection{Percentage Subjects That Achieved Therapeutic Threshold}

The generally-accepted therapeutic threshold for zolpidem for treatment of insomnia is a plasma concentration at and above $20 \mathrm{ng} / \mathrm{mL}$ [34] [47] [48]. Applying this criterion to the data shown in Figure 2, leads to the following determinations of time to attain effective plasma concentration threshold: zolpidem LS $10 \mathrm{mg} 7.0 \mathrm{~min}$, zolpidem LS $5 \mathrm{mg} 10.5 \mathrm{~min}$, AMBIEN $10 \mathrm{mg} 15.0 \mathrm{~min}$, and AMBIEN $5 \mathrm{mg} 17.2 \mathrm{~min}$.

The percentage of participants who attained the therapeutic threshold of 20 $\mathrm{ng} / \mathrm{mL}$ as a function of time for zolpidem LS and AMBIEN is shown as composite in Figure 4, for the 5-mg doses in Figure 5, and for the 10-mg doses in Figure 5. At both doses (5-mg and 10-mg), the percentage of responders increased at a faster rate following zolpidem LS than following AMBIEN.

Comparison of the pharmacokinetic parameters that demonstrate a more rapid sleep onset with lingual-spray vs oral-tablet delivery of zolpidem are summarized in Table 1.
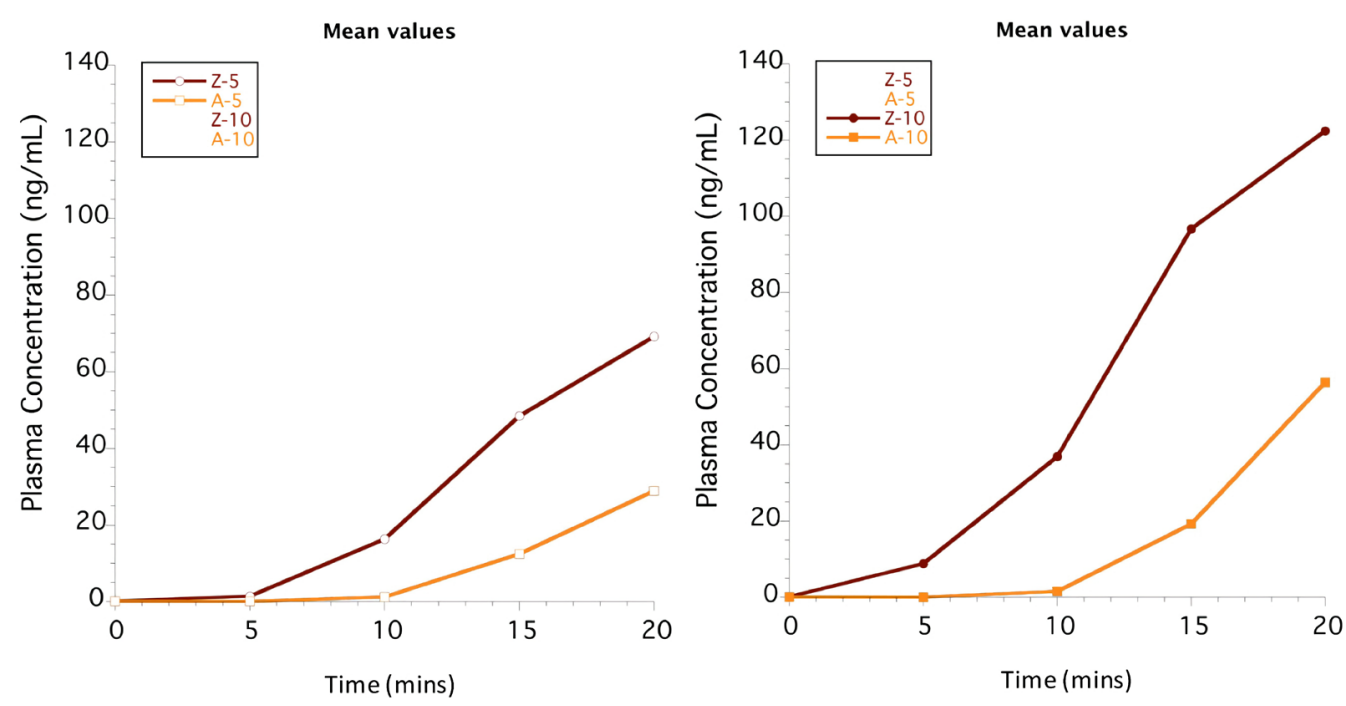

Figure 3. Mean plasma concentration following $5 \mathrm{mg}$ (left panel) or $10 \mathrm{mg}$ (right panel) zolpidem LS (Z) or tablets (A). 


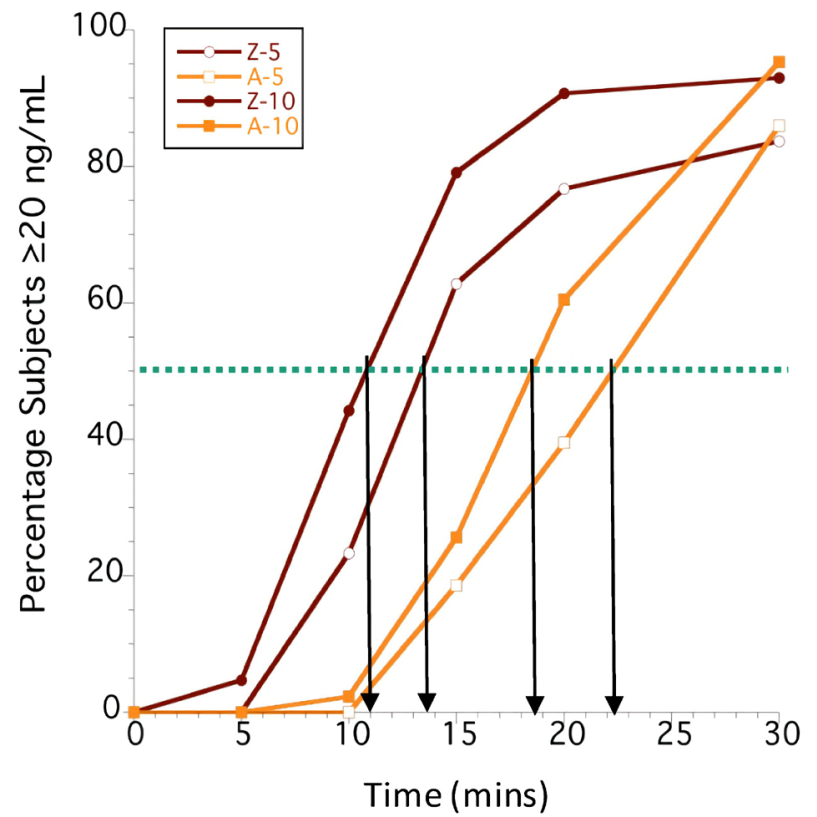

Figure 4. Percent reaching threshold following $5 \mathrm{mg}$ or $10 \mathrm{mg}$ zolpidem LS (Z) or tablets (A).
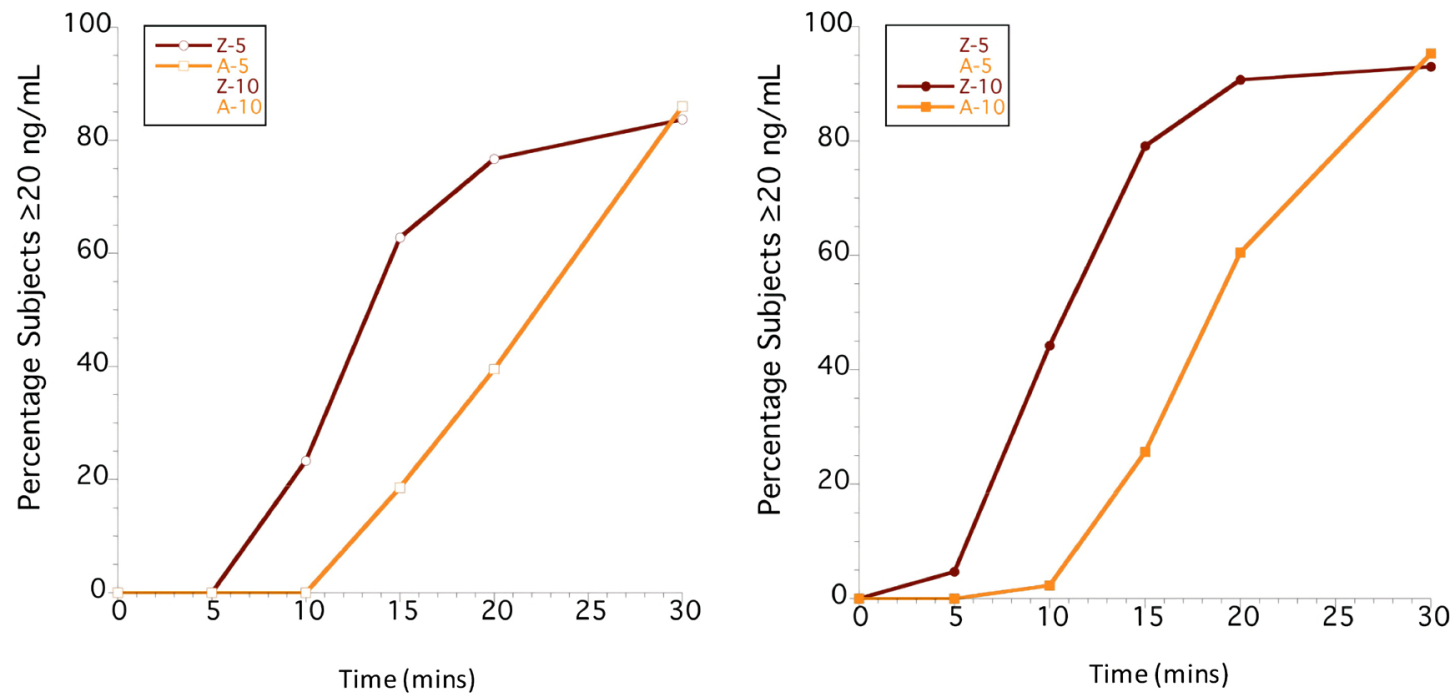

Figure 5. Percent reaching threshold following $5 \mathrm{mg}$ (left panel) or $10 \mathrm{mg}$ (right panel) zolpidem LS (Z) or tablets (A).

Table 1. Summary comparison of zolipem LS vs oral tablets.

\begin{tabular}{cccc}
\hline \multirow{2}{*}{ Study Group } & \multicolumn{3}{c}{ Time (mins) to Pharmacokinetic and Pharmacodynamic Endpoints } \\
\cline { 2 - 4 } & $\begin{array}{c}\text { Threshold plasma } \\
\text { Concentration }^{\mathrm{a}}\end{array}$ & $\begin{array}{c}\text { Time to 50\% } \\
\text { Responders }^{\mathrm{a}}\end{array}$ & $\begin{array}{r}\text { Time to 5-point } \\
\text { Change in DSST }^{\mathrm{b}}\end{array}$ \\
\hline Zolpidem LS 10 mg & 7.0 & 11.0 & 4.8 \\
Zolpidem LS 5 mg & 10.5 & 13.5 & 8.0 \\
AMBIEN 10 mg & 15.0 & 18.5 & 14.0 \\
AMBIEN 5 mg & 17.2 & 22.2 & 16.2 \\
\hline
\end{tabular}

${ }^{\mathrm{a}} \geq 20 \mathrm{ng} / \mathrm{mL} ;{ }^{\mathrm{b} C o m p a r e d ~ t o ~ b a s e l i n e . ~}$ 


\subsection{Efficacy}

Two potential indications of therapeutic efficacy were measured in the study: a visual analog scale (VAS), and change from baseline in the Digit Symbol Substitution Test (DSST). The VAS test turned out to be an unreliable measure. It yielded only sporadic differences, and there was no apparent pattern or consistency with reference to when the differences were observed. Consequently, only the DSST is summarized below.

\subsubsection{Onset of Sleepiness}

In contrast to the VAS, which proved to be an unreliable indicator, the change from baseline in the DSST provided reliable results. The results for the mean change from baseline for all groups (zolpidem LS 5 and $10 \mathrm{mg}$ and AMBIEN 5 and $10 \mathrm{mg}$ ) as a function of time during the first 22 minutes following administration are shown in Figure 6. This encompasses the time of onset of therapeutic effect and it allows comparison of the formulations. As expected, there is a dose-related relationship for both formulations. That is, the 10-mg dose of each formulation (zolpidem LS and AMBIEN) resulted in a more rapid increase in "sleepiness" by zolpidem than did the 5-mg dose of each formulation (intra-formulation comparison).

With regard to comparison of the two formulations (inter-dose formulation): the zolpidem-induced "sleepiness" rose more rapidly after 5-mg zolpidem LS compared to 5-mg AMBIEN (Figure 7), and zolpidem-induced sleepiness rose more rapidly following 10-mg zolpidem LS compared to 10-mg AMBIEN (Figure 7). In fact, the 5-mg dose of zolpidem LS formulation resulted in a faster increase in zolpidem-induced sleepiness than did the 10-mg dose of AMBIEN (Figure 6).

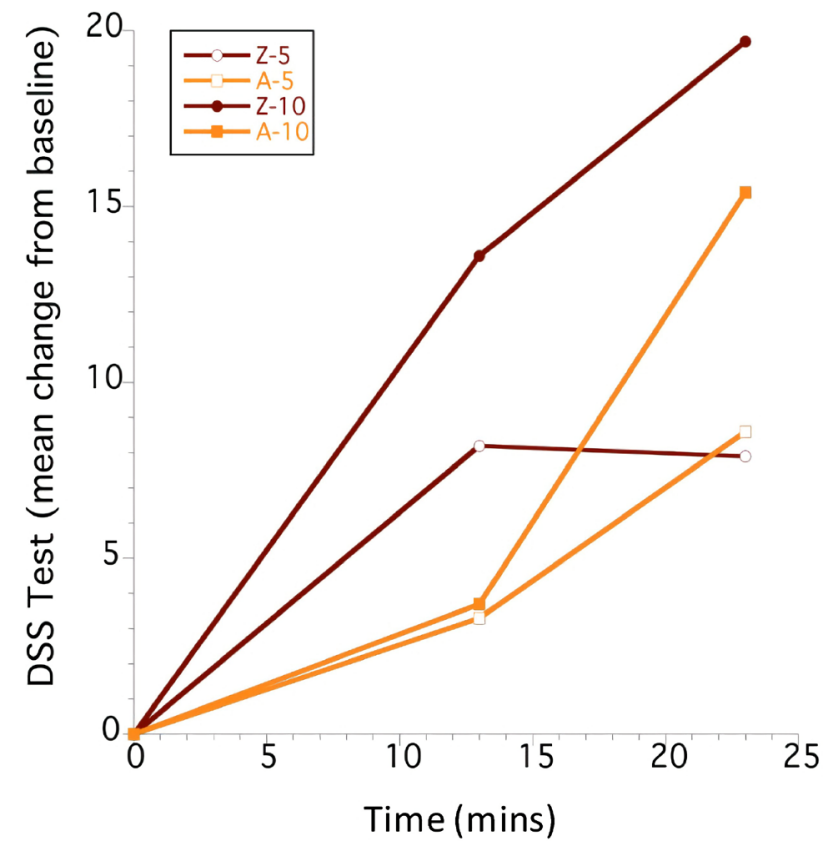

Figure 6. Change in DSST from baseline following $5 \mathrm{mg}$ or $10 \mathrm{mg}$ zolpidem LS (Z) or tablets (A). 

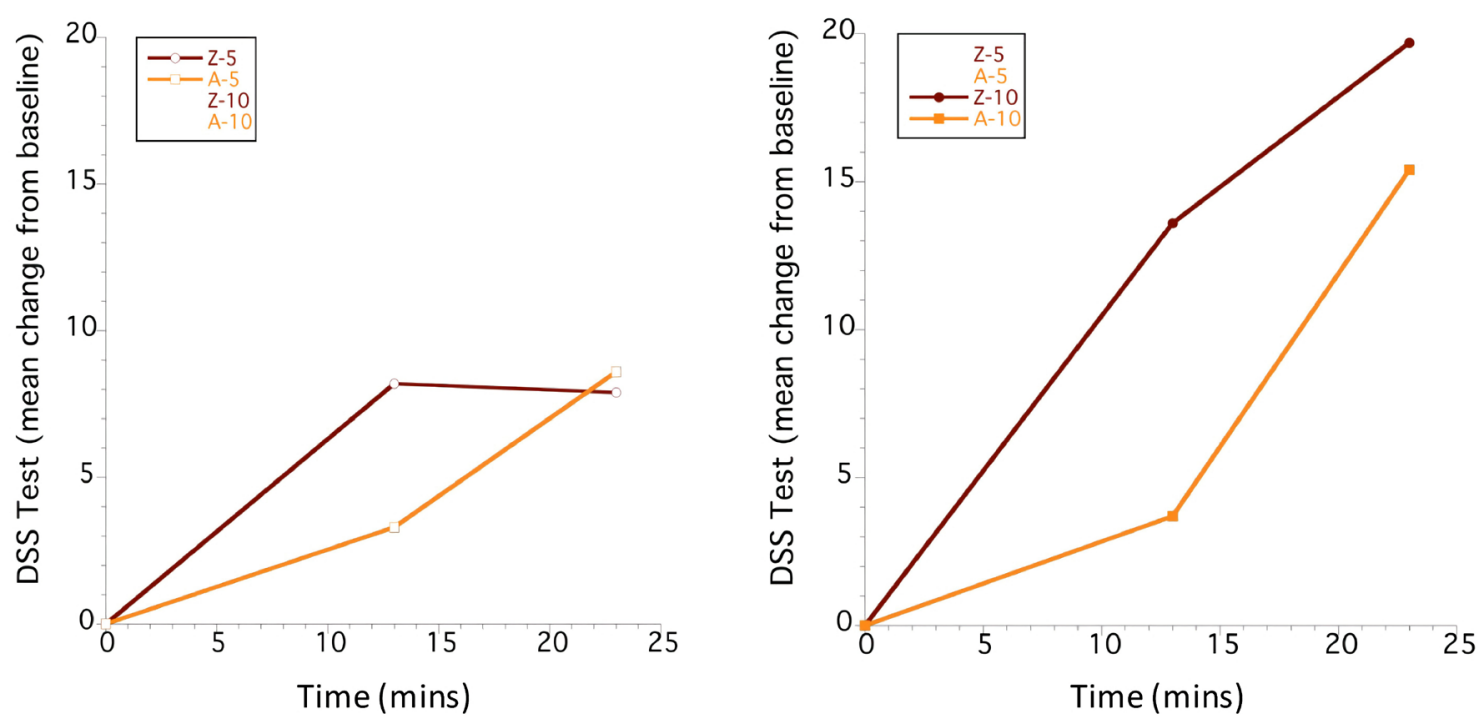

Figure 7. Change in DSST from baseline following $5 \mathrm{mg}$ (left panel) or $10 \mathrm{mg}$ (right panel) zolpidem LS (Z) or tablets (A).

\subsubsection{Comparison of Zolpidem LS vs AMBIEN}

The comparison of zolpidem LS vs AMBIEN is summarized in Table 1.

\subsection{Safety}

The most common AEs experienced by study participants were diplopia, dizziness, euphoric mood, headache, and nausea. Only dizziness occurred in more participants after zolpidem LS $(10 \mathrm{mg})$ than after AMBIEN $(10 \mathrm{mg})$. In order of decreasing incidence of AEs, dizziness, diplopia, and headache were the most common among female participants, while euphoric mood, diplopia, and dizziness were the most common among male participants. No deaths or serious adverse effects (SAEs) occurred during the study.

There were no AEs indicative of local adverse reactions in the oral cavity after treatment with zolpidem LS (either $5 \mathrm{mg}$ or $10 \mathrm{mg}$ ).

\section{Conclusions}

We report the results of a study that compared pharmacokinetic, efficacy, and safety/tolerability measures of a zolpidem lingual spray compared to zolpidem oral tablets in healthy volunteers. Greater absorption rates of zolpidem LS were also manifested in significantly earlier detectable levels up to 20 minutes following administration. The time to a zolpidem plasma concentration associated with sedation was significantly less for the zolpidem LS formulation than of the zolpidem oral tablet, which is related to a faster onset of sleepiness. Overall, zolpidem LS was safe and well-tolerated, with no signs of oral irritation on examination. There were few AEs, no SAEs either locally or systemically, and no clinically significant change in physical status. A weakness of the study is that it was only single-center and open-label.

In summary, the lingual spray formulation provided more rapid attainment of 
plasma concentrations of zolpidem, more rapid attainment of therapeutic threshold plasma concentration, and faster therapeutic efficacy (sleepiness) than did standard zolpidem oral tablets. In addition, zolpidem LS had a good safety/tolerability profile, and features desirable for convenient and effective use.

\section{Conflicts of Interest}

The authors declare no conflicts of interest regarding the publication of this paper.

\section{References}

[1] National Institutes of H. (2005) National Institutes of Health State of the Science Conference Statement on Manifestations and Management of Chronic Insomnia in Adults, June 13-15, 2005. Sleep, 28, 1049-1057.

https://doi.org/10.1093/sleep/28.9.1049

[2] Benca, R.M. (2001) Consequences of Insomnia and Its Therapies. Journal of Clinical Psychiatry, 62, 33-38.

[3] Bramoweth, A.D. and Taylor, D.J. (2012) Chronic Insomnia and Health Care Utilization in Young Adults. Behavioral Sleep Medicine, 10, 106-121.

https://doi.org/10.1080/15402002.2011.587067

[4] Agargün, M.Y., Kara, H. and Solmaz, M. (1997) Sleep Disturbances and Suicidal Behavior in Patients with Major Depression. Journal of Clinical Psychiatry, 58, 249-251. https://doi.org/10.4088/JCP.v58n0602

[5] McCall, W.V., et al. (2010) Insomnia Severity Is an Indicator of Suicidal Ideation during a Depression Clinical Trial. Sleep Medicine, 11, 822-827.

https://doi.org/10.1016/j.sleep.2010.04.004

[6] Norra, C., Richter, N. and Juckel, G. (2011) Sleep Disturbances and Suicidality: A Common Association to Look for in Clinical Practise and Preventive Care. EPMA Journal, 2, 295-307. https://doi.org/10.1007/s13167-011-0101-2

[7] Spiegel, K., Tasali, E., Leproult, R. and Van Cauter, E. (2009) Effects of Poor and Short Sleep on Glucose Metabolism and Obesity Risk. Nature Reviews Endocrinology, 5, 253-261. https://doi.org/10.1038/nrendo.2009.23

[8] Hublin, C., Partinen, M., Koskenvuo, M. and Kaprio, J. (2011) Heritability and Mortality Risk of Insomnia-Related Symptoms: A Genetic Epidemiologic Study in a Population-Based Twin Cohort. Sleep, 34, 957-964.

https://doi.org/10.5665/SLEEP.1136

[9] Fava, M., et al. (2009) Zolpidem Extended-Release Improves Sleep and Next-Day Symptoms in Comorbid Insomnia and Generalized Anxiety Disorder. Journal of Clinical Psychopharmacology, 29, 222-230.

https://doi.org/10.1097/JCP.0b013e3181a390ba

[10] Pollack, M., et al. (2008) Eszopiclone Coadministered with Escitalopram in Patients with Insomnia and Comorbid Generalized Anxiety Disorder. Archives of General Psychiatry, 65, 551-562. https://doi.org/10.1001/archpsyc.65.5.551

[11] Roth, T., et al. (2009) The Effect of Eszopiclone in Patients with Insomnia and Coexisting Rheumatoid Arthritis: A Pilot Study. Prim Care Companion Journal of Clinical Psychiatry, 11, 292-301. https://doi.org/10.4088/PCC.08m00749bro

[12] Buysse, D.J. (2008) Chronic Insomnia. American Journal of Psychiatry, 165, 678-686. https://doi.org/10.1176/appi.ajp.2008.08010129 
[13] Morin, C.M., et al. (2009) Cognitive Behavioral Therapy, Singly and Combined with Medication, for Persistent Insomnia: A Randomized Controlled Trial. JAMA, 301, 2005-2015. https://doi.org/10.1001/jama.2009.682

[14] Riemann, D., et al. (2011) Chronic Insomnia: Clinical and Research Challenges-An Agenda. Pharmacopsychiatry, 44, 1-14.

[15] Yang, C.M., Lin, S.C. and Cheng, C.P. (2013) Transient Insomnia versus Chronic Insomnia: A Comparison Study of Sleep-Related Psychological/Behavioral Characteristics. Journal of Clinical Psychology, 69, 1094-1107. https://doi.org/10.1002/jclp.22000

[16] Stepanski, E., Zorick, F., Roehrs, T., Young, D. and Roth, T. (1988) Daytime Alertness in Patients with Chronic Insomnia Compared with Asymptomatic Control Subjects. Sleep, 11, 54-60. https://doi.org/10.1093/sleep/11.1.54

[17] Bonnet, M.H. and Arand, D.L. (1995) 24-Hour Metabolic Rate in Insomniacs and Matched Normal Sleepers. Sleep, 18, 581-588. https://doi.org/10.1093/sleep/18.7.581

[18] Pinto, L.R., et al. (2010) New Guidelines for Diagnosis and Treatment of Insomnia. Arquivos de Neuro-Psiquiatria, 68, 666-675. https://doi.org/10.1590/S0004-282X2010000400038

[19] Arroll, B., et al. (2012) Prevalence of Causes of Insomnia in Primary Care: A Cross-Sectional Study. British Journal of General Practice, 62, e99-e103. https://doi.org/10.3399/bjgp12X625157

[20] Pearson, N.J., Johnson, L.L. and Nahin, R.L. (2006) Insomnia, Trouble Sleeping, and Complementary and Alternative Medicine: Analysis of the 2002 National Health Interview survey Data. Archives of Internal Medicine, 166, 1775-1782. https://doi.org/10.1001/archinte.166.16.1775

[21] Vgontzas, A.N., et al. (2001) Chronic Insomnia Is Associated with Nyctohemeral Activation of the Hypothalamic-Pituitary-Adrenal Axis: Clinical Implications. The Journal of Clinical Endocrinology \& Metabolism, 86, 3787-3794. https://doi.org/10.1210/jc.86.8.3787

[22] Roth, T., Roehrs, T. and Pies, R. (2007) Insomnia: Pathophysiology and Implications for Treatment. Sleep Medicine Reviews, 11, 71-79. https://doi.org/10.1016/j.smrv.2006.06.002

[23] Lie, J.D., Tu, K.N., Shen, D.D. and Wong, B.M. (2015) Pharmacological Treatment of Insomnia. $P T, 40,759-771$.

[24] Asnis, G.M., Caneva, E. and Henderson, M.A. (2016) A Review of Antidepressant-Induced Urinary Hesitancy: A Focus on Levomilnacipran ER Including Two Case Presentations (5633). Expert Opinion on Drug Safety, 15, 717-725. https://doi.org/10.1517/14740338.2016.1164138

[25] Schutte-Rodin, S., Broch, L., Buysse, D., Dorsey, C. and Sateia, M. (2008) Clinical Guideline for the Evaluation and Management of Chronic Insomnia in Adults. Journal of Clinical Sleep Medicine, 4, 487-504.

[26] Möhler, H. (2006) GABAA Receptors in Central Nervous System Disease: Anxiety, Epilepsy, and Insomnia. Journal of Receptor and Signal Transduction Research, 26, 731-740. https://doi.org/10.1080/10799890600920035

[27] Gerashchenko, D., et al. (2008) Identification of a Population of Sleep-Active Cerebral Cortex Neurons. Proceedings of the National Academy of Sciences of the United States of America, 105, 10227-10232.

https://doi.org/10.1073/pnas.0803125105 
[28] Winsky-Sommerer, R. (2009) Role of GABAA Receptors in the Physiology and Pharmacology of Sleep. European Journal of Neuroscience, 29, 1779-1794. https://doi.org/10.1111/j.1460-9568.2009.06716.x

[29] Morin, A.K., Jarvis, C.I. and Lynch, A.M. (2007) Therapeutic Options for Sleep-Maintenance and Sleep-Onset Insomnia. Pharmacotherapy, 27, 89-110. https://doi.org/10.1592/phco.27.1.89

[30] Passarella, S. and Duong, M.T. (2008) Diagnosis and Treatment of Insomnia. American Journal of Health-System Pharmacy, 65, 927-934. https://doi.org/10.2146/ajhp060640

[31] Holbrook, A.M., Crowther, R., Lotter, A., Cheng, C. and King, D. (2000) Meta-Analysis of Benzodiazepine Use in the Treatment of Insomnia. CMAJ, 162, 225-233.

[32] Longo, L.P. and Johnson, B. (2000) Addiction: Part I. Benzodiazepines-Side Effects, Abuse Risk and Alternatives. American Family Physician, 61, 2121-2128.

[33] American Geriatrics Society Beers Criteria Update Expert, P. (2012) American Geriatrics Society Updated Beers Criteria for Potentially Inappropriate Medication Use in Older Adults. Journal of the American Geriatrics Society, 60, 616-631. https://doi.org/10.1111/j.1532-5415.2012.03923.x

[34] Patat, A., et al. (1994) EEG Profile of Intravenous Zolpidem in Healthy Volunteers. Psychopharmacology, 114, 138-146. https://doi.org/10.1007/BF02245455

[35] Garrigou-Gadenne, D., et al. (1989) Pharmacokinetics, Brain Distribution and Pharmaco-Electrocorticographic Profile of Zolpidem, a New Hypnotic, in the Rat. Journal of Pharmacology and Experimental Therapeutics, 248, 1283-1288.

[36] Kryger, M.H., Steljes, D., Pouliot, Z., Neufeld, H. and Odynski, T. (1991) Subjective versus Objective Evaluation of Hypnotic Efficacy: Experience with Zolpidem. Sleep, 14, 399-407. https://doi.org/10.1093/sleep/14.5.399

[37] Monti, J.M. (1989) Effect of Zolpidem on Sleep in Insomniac Patients. European Journal of Clinical Pharmacology, 36, 461-466. https://doi.org/10.1007/BF00558070

[38] Nicholson, A.N. and Pascoe, P.A. (1986) Hypnotic Activity of an Imidazo-Pyridine (Zolpidem). British Journal of Clinical Pharmacology, 21, 205-211. https://doi.org/10.1111/j.1365-2125.1986.tb05176.x

[39] Balkin, T.J., O’Donnell, V.M., Wesensten, N., McCann, U. and Belenky, G. (1992) Comparison of the Daytime Sleep and Performance Effects of Zolpidem versus Triazolam. Psychopharmacology, 107, 83-88. https://doi.org/10.1007/BF02244970

[40] Bensimon, G., et al. (1990) Daytime Wakefulness Following a Bedtime Oral Dose of Zolpidem $20 \mathrm{mg}$, Flunitrazepam $2 \mathrm{mg}$ and Placebo. British Journal of Clinical Pharmacology, 30, 463-469. https://doi.org/10.1111/j.1365-2125.1990.tb03798.x

[41] Brunner, D.P., Dijk, D.J., Munch, M. and Borbely, A.A. (1991) Effect of Zolpidem on Sleep and Sleep EEG Spectra in Healthy Young Men. Psychopharmacology, 104, 1-5. https://doi.org/10.1007/BF02244546

[42] Fairweather, D.B., Kerr, J.S. and Hindmarch, I. (1992) The Effects of Acute and Repeated Doses of Zolpidem on Subjective Sleep, Psychomotor Performance and Cognitive Function in Elderly Volunteers. European Journal of Clinical Pharmacology, 43, 597-601. https://doi.org/10.1007/BF02284957

[43] Merlotti, L., et al. (1989) The Dose Effects of Zolpidem on the Sleep of Healthy Normals. Journal of Clinical Psychopharmacology, 9, 9-14. https://doi.org/10.1097/00004714-198902000-00003

[44] Lader, M. (1992) Rebound Insomnia and Newer Hypnotics. Psychopharmacology, 
108, 248-255. https://doi.org/10.1007/BF02245108

[45] Dunne, S., Shannon, B., Dunne, C. and Cullen, W. (2013) A Review of the Differences and Similarities between Generic Drugs and Their Originator Counterparts, Including Economic Benefits Associated with Usage of Generic Medicines, Using Ireland as a Case Study. BMC Pharmacology and Toxicology, 14, 1.

https://doi.org/10.1186/2050-6511-14-1

[46] Andrade, C. (2015) Bioequivalence of Generic Drugs: A Simple Explanation for a US Food and Drug Administration Requirement. Journal of Clinical Psychiatry, 76, e742-e744. https://doi.org/10.4088/JCP.15f10094

[47] Li, C.T., et al. (2016) Pharmacokinetics of a Novel Zolpidem Nasal Spray for Rapid Management of Insomnia: First Trial in Humans. Journal of Clinical Sleep Medicine, 12, 1453-1459. https://doi.org/10.5664/jcsm.6264

[48] Neubauer, D.N. (2010) ZolpiMist: A New Formulation of Zolpidem Tartrate for the Short-Term Treatment of Insomnia in the US. Nature and Science of Sleep, 2, 79-84. https://doi.org/10.2147/NSS.S6431 